\title{
Microbial oxidation of arsenite in a subarctic environment: diversity of arsenite oxidase genes and identification of a psychrotolerant arsenite oxidiser
}

Thomas H Osborne ${ }^{1}$, Heather E Jamieson ${ }^{2}$, Karen A Hudson-Edwards ${ }^{3}$, D Kirk Nordstrom ${ }^{4}$, Stephen R Walker ${ }^{2}$, Seamus A Ward ${ }^{5}$, Joanne M Santini ${ }^{1 *}$

\begin{abstract}
Background: Arsenic is toxic to most living cells. The two soluble inorganic forms of arsenic are arsenite $(+3)$ and arsenate $(+5)$, with arsenite the more toxic. Prokaryotic metabolism of arsenic has been reported in both thermal and moderate environments and has been shown to be involved in the redox cycling of arsenic. No arsenic metabolism (either dissimilatory arsenate reduction or arsenite oxidation) has ever been reported in cold environments (i.e. $<10^{\circ} \mathrm{C}$ ).

Results: Our study site is located 512 kilometres south of the Arctic Circle in the Northwest Territories, Canada in an inactive gold mine which contains mine waste water in excess of $50 \mathrm{mM}$ arsenic. Several thousand tonnes of arsenic trioxide dust are stored in underground chambers and microbial biofilms grow on the chamber walls below seepage points rich in arsenite-containing solutions. We compared the arsenite oxidisers in two subsamples (which differed in arsenite concentration) collected from one biofilm. 'Species' (sequence) richness did not differ between subsamples, but the relative importance of the three identifiable clades did. An arsenite-oxidising bacterium (designated GM1) was isolated, and was shown to oxidise arsenite in the early exponential growth phase and to grow at a broad range of temperatures $\left(4-25^{\circ} \mathrm{C}\right)$. Its arsenite oxidase was constitutively expressed and functioned over a broad temperature range.

Conclusions: The diversity of arsenite oxidisers does not significantly differ from two subsamples of a microbial biofilm that vary in arsenite concentrations. GM1 is the first psychrotolerant arsenite oxidiser to be isolated with the ability to grow below $10^{\circ} \mathrm{C}$. This ability to grow at low temperatures could be harnessed for arsenic bioremediation in moderate to cold climates.
\end{abstract}

\section{Background}

Arsenic's toxic and medicinal properties have been appreciated for more than two millennia [1]. Its two soluble inorganic forms, arsenite $(+3)$ and arsenate $(+5)$, entering drinking water from natural sources, have caused poisoning in Taiwan, Chile, Argentina, Bangladesh and West Bengal, and most recently arsenicosis (arsenic poisoning) has been detected in people from Cambodia, Vietnam, Nepal, China, Inner Mongolia,

\footnotetext{
* Correspondence: j.santini@ucl.ac.uk

${ }^{1}$ Institute of Structural and Molecular Biology, UCL, Darwin Building, Gower
} Street, London WC1E 6BT, UK
Bolivia and Mexico [2,3]. In addition, arsenic contamination due to anthropogenic activity (e.g. mining) is increasing in importance in parts of the USA, Canada, Australia, Argentina and Mexico [4]. Although arsenic is toxic to most organisms, some prokaryotes have evolved mechanisms to gain energy by either oxidising or reducing it $[5,6]$.

Prokaryotic arsenic metabolism has been detected in hydrothermal and temperate environments and has been shown to be involved in the redox cycling of arsenic [7-10]. The arsenite-oxidising bacteria isolated so far are phylogenetically diverse. The oxidation of arsenite may yield useable energy or may merely form part of a

\section{Biomed Central}


detoxification process [6]. To date, all aerobic arsenite oxidation involves the arsenite oxidase that contains two heterologous subunits: AroA (also known as AoxB) and AroB (also known as AoxA) [6]. AroA is the large catalytic subunit that contains the molybdenum cofactor and a $3 \mathrm{Fe}-4 \mathrm{~S}$ cluster and AroB contains a Rieske 2Fe-2S cluster [6].

Although arsenic metabolism has been detected in both moderate and high-temperature environments, and mesophilic and thermophilic arsenite oxidisers have been isolated, no arsenic metabolism (either dissimilatory arsenate reduction or arsenite oxidation) has ever been detected in cold environments (i.e. $<10^{\circ} \mathrm{C}$ ). One such environment with high concentrations of arsenic is the Giant Mine, one of Canada's oldest and largest gold mines. It is located a few kilometres north of Yellowknife, Northwest Territories, $62^{\circ}$ north of the equator and 512 kilometres south of the Arctic Circle. Gold was produced from 1948 to 1999 by roasting arsenopyrite (FeAsS)-bearing ore. The mine now contains approximately 300,000 tonnes of arsenic trioxide, stored in underground chambers [11]. Temperatures in the underground stopes range from $4^{\circ} \mathrm{C}$ to $10^{\circ} \mathrm{C}[11]$.

Here we report the detection, isolation and characterisation of an aerobic psychrotolerant arsenite-oxidising bacterium from a subterranean biofilm in the Giant Mine. Unlike other characterised arsenite oxidisers, this organism is capable of growing below $10^{\circ} \mathrm{C}$ and is the first heterotrophic organism to oxidise arsenite in the early exponential phase of growth. We also compare the diversity of arsenite oxidisers in two subsamples of the biofilm that vary in arsenite concentrations.

\section{Results and Discussion}

The Giant Mine has a long history of arsenic contamination and dissolution of stored arsenic trioxide by infiltrating groundwaters has increased arsenic concentrations at this site from a few to $50 \mathrm{mM}$. Biofilms have formed at many places where water seeps into the underground excavations [11]. One such biofilm (Figure 1a) was located growing in an abandoned stope below seepage from a diamond drill hole approximately $152 \mathrm{~m}$ below the arsenic trioxide chambers $(230 \mathrm{~m}$ below land surface) (temperature at each time of sampling was ca. $4^{\circ}$ C). Water taken from the top of the biofilm in 2006 contained $14.01 \mathrm{mM}$ total soluble arsenic and $2.56 \mathrm{mM}$ arsenite. Samples taken in 2007 from the top and bottom of the biofilm contained $9.57 \mathrm{mM}$ total soluble arsenic and $9.22 \mathrm{mM}$ arsenite (top) and $9.16 \mathrm{mM}$ total soluble arsenic and 6.01 $\mathrm{mM}$ arsenite (bottom). The concentration of arsenite in the 2006 sample was substantially lower than that of the equivalent top sample from 2007. The reason for this was probably microbial arsenite oxidation during storage as the liquid was not extracted from the 2006 sample until 18 days after collection whereas the liquid was extracted immediately from the 2007 samples. SEM examination of the biofilm revealed the presence of threadlike extracellular polymeric substances and distinct microorganisms (Figure 1b).

The arsenite-oxidising bacterium, designated GM1 was isolated and found to be a Gram-negative, rod-shaped, motile, heterotroph. Phylogenetic analysis of its full $16 \mathrm{~S}$ rRNA gene sequence (Figure 2) showed it to be a member of the Betaproteobacteria related to Polaromonas species. GM1 is closely related (98\% sequence identity) to Polaromonas sp. JS666, a cis-dichloroethene-degrading bacterium isolated from granular activated carbon from Dortmund, Germany [12], and Polaromonas napthalenivorans CJ2 a naphthalene-degrading bacterium isolated from a coal-tar contaminated aquifer in New York state, USA [13]. Using the CLASSIFIER tool

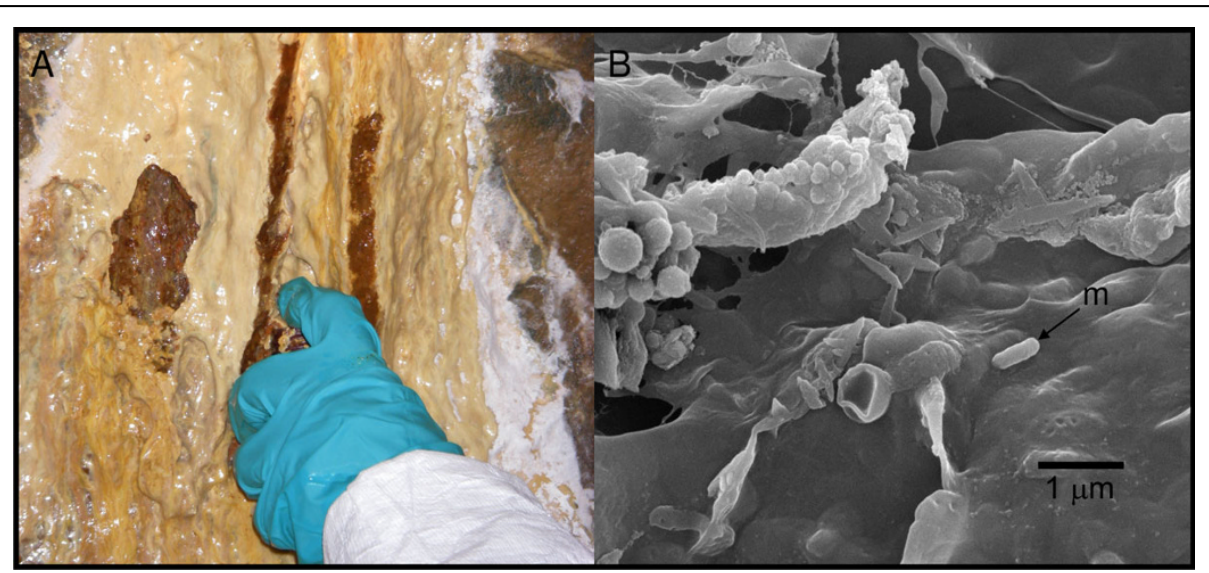

Figure 1 Microbial biofilm sampled from Giant Mine, Yellowknife, NWT, Canada. (A) Microbial biofilm. The mineral yukonite, a Ca-Fe arsenate is shown by the reddish-brown colouration. (B) Scanning electron micrograph of biofilm showing extracellular polymeric substance (EPS) which appear as threads and microbes $(m)$. 


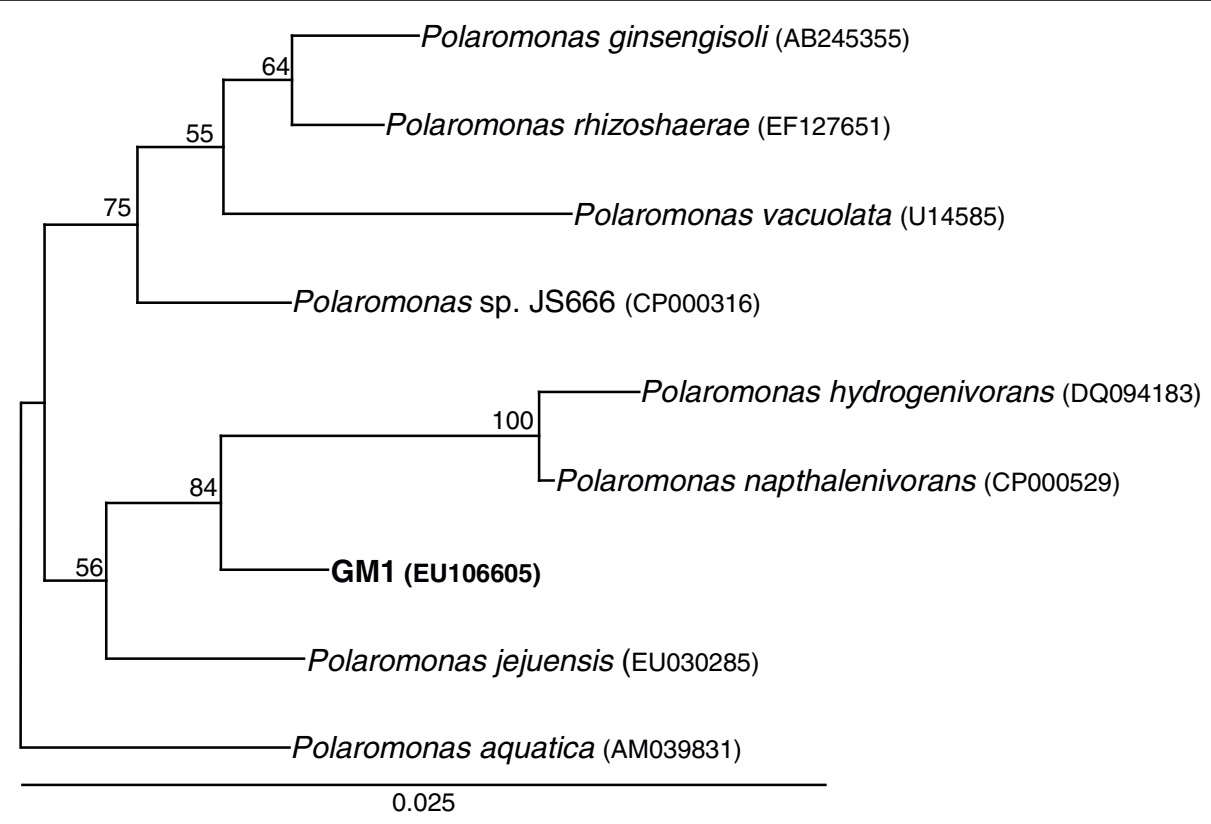

Figure 2 16S rRNA phylogenetic tree of arsenite-oxidising strain GM1 and published Polaromonas species. GenBank accession numbers are in parentheses. Significant bootstrap values (per 100 trials) are shown. The tree is rooted with the 16S rRNA gene sequence of Alcaligenes faecalis (AY027506) (not shown).

of the Ribosomal Database Project we classed GM1 as a Polaromonas species [14] and the first capable of oxidising arsenite. Unlike its phylogenetic relatives GM1 was unable to grow with either cis-dichloroethene or naphthalene as sole carbon source (data not shown).

Growth of GM1 was tested at $4{ }^{\circ} \mathrm{C}, 10^{\circ} \mathrm{C}$ and $20^{\circ} \mathrm{C}$ in a minimal salts medium (MSM) with $0.04 \%(\mathrm{w} / \mathrm{v})$ yeast extract in the presence and absence of $4 \mathrm{mM}$ arsenite as described previously [15] (Note: GM1 was unable to grow chemolithoautotrophically with arsenite). Under all conditions arsenite was oxidised to arsenate and oxidation occurred in the early exponential phase of growth (Figure 3). The generation time of GM1 was shorter in the absence of arsenite, and decreased with increasing temperature (without arsenite at $4^{\circ} \mathrm{C}, 10^{\circ} \mathrm{C}$ and $20^{\circ} \mathrm{C}: 19$ $\mathrm{h}, 16.5 \mathrm{~h}$ and $7 \mathrm{~h}$, respectively; with arsenite at $4^{\circ} \mathrm{C}, 10^{\circ}$ $\mathrm{C}$ and $20^{\circ} \mathrm{C}: 21.5 \mathrm{~h}, 17.7 \mathrm{~h}$ and $8.5 \mathrm{~h}$, respectively). GM1 did not grow above $25^{\circ} \mathrm{C}$. To date, only one arsenite oxidiser has been demonstrated to grow below $20^{\circ} \mathrm{C}$ [16]. This organism, a chemolithoautotrophic arsenite oxidiser designated M14, is a member of the Alphaproteobacteria related to Sinorhizobium species. M14's temperature range was between $10^{\circ} \mathrm{C}$ and $37^{\circ} \mathrm{C}$ with an optimum of $22^{\circ} \mathrm{C}$ [16]. GM1 is the first reported arsenite oxidiser capable of growth below $10^{\circ} \mathrm{C}$.

The arsenite-oxidising ability of GM1 was further confirmed by testing for arsenite oxidase (Aro) activity in cells grown in the MSM with $4 \mathrm{mM}$ arsenite and $0.04 \%$ $(\mathrm{w} / \mathrm{v})$ yeast extract. Aro activity was measured at room temperature (i.e. $24^{\circ} \mathrm{C}$ ) in its optimal buffer, $50 \mathrm{mM} \mathrm{2-}$ (N-Morpholino)ethanesulfonic acid (MES) ( $\mathrm{pH}$ 5.5) (data not shown). Aro activity was higher when GM1 was grown at $10^{\circ} \mathrm{C}(0.334 \mathrm{U} / \mathrm{mg})$ compared with growth at $4^{\circ} \mathrm{C}(0.247 \mathrm{U} / \mathrm{mg})$ and $20^{\circ} \mathrm{C}(0.219 \mathrm{U} / \mathrm{mg})$ which were comparable. In growth experiments although all the arsenite is oxidised to arsenate in the early exponential growth phase the highest Aro activity was observed in the stationary phase of growth (i.e. $0.334 \mathrm{U} / \mathrm{mg}$ compared with $0.236 \mathrm{U} / \mathrm{mg}$ at early exponential phase).

In most cases, arsenite is required in the growth medium for arsenite oxidase gene expression [6]. There are two exceptions, Thiomonas sp. str. 3As and Agrobacterium tumefaciens str. 5A, where the arsenite oxidase is expressed when the organisms are grown in the absence of arsenite but in the latter the expression does not occur until stationary phase $[17,18]$. In GM1 arsenite oxidase expression is also constitutive when grown in the absence of arsenite [i.e. in the MSM with $0.04 \%$ (w/ v) yeast extract] with $0.367 \mathrm{U} / \mathrm{mg}$ observed in late exponential phase and activity also detected in early exponential phase $(0.13 \mathrm{U} / \mathrm{mg})$. Taken together this information suggests that there are at least two modes of regulating the expression of the aro genes in GM1, possibly a two-component signal transduction system and quorum sensing. Because of the broad temperature range for growth of GM1, arsenite oxidase activity was determined at a variety of temperatures (Figure 4). Activity occurred over a broad temperature range 

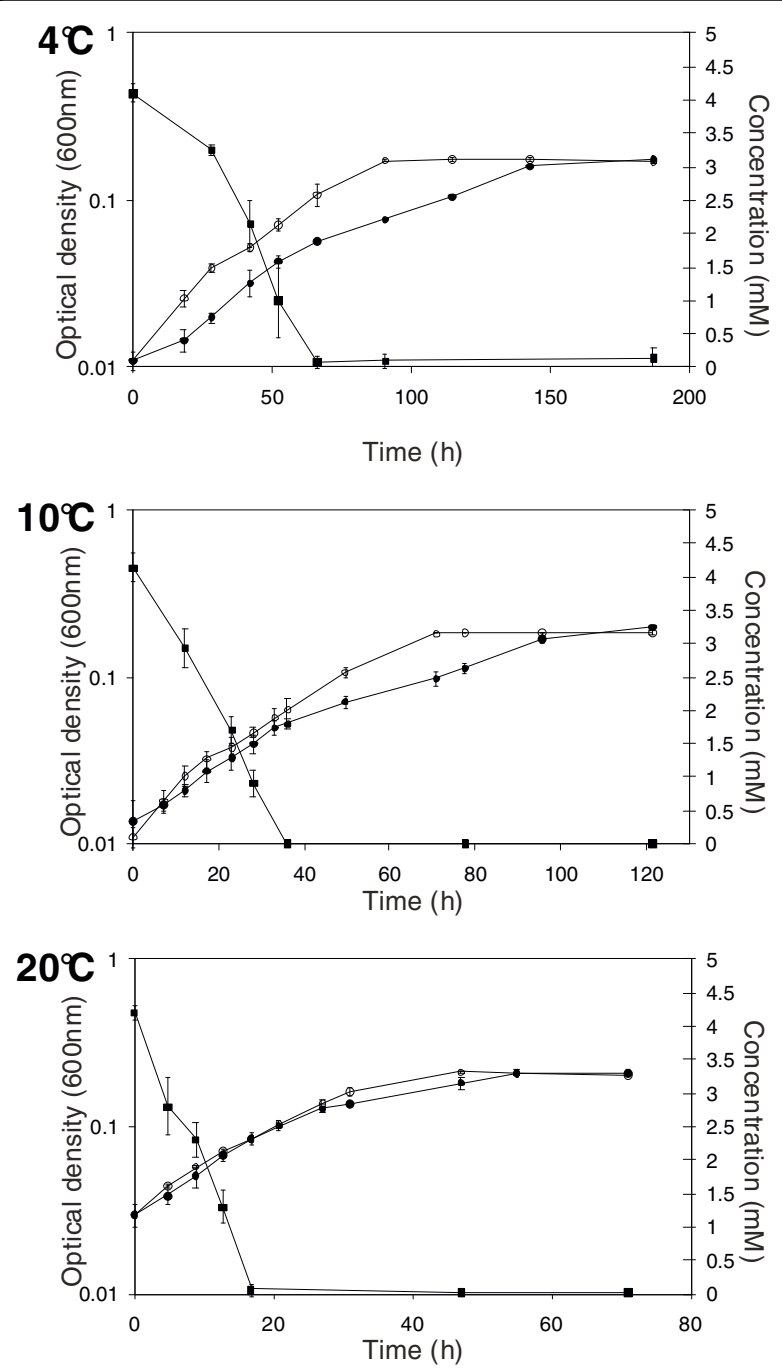

Figure 3 Growth curves of $\mathrm{GM} 1$ grown at $4^{\circ} \mathrm{C}, 10^{\circ} \mathrm{C}$ and $20^{\circ} \mathrm{C}$ in the Minimal Salts Medium (MSM) with $0.04 \%(\mathrm{w} / \mathrm{v})$ yeast extract. With $4 \mathrm{mM}$ arsenite, closed circle; without arsenite, open circle; arsenite concentration, closed square. Error bars are the standard deviation of multiple experiments.

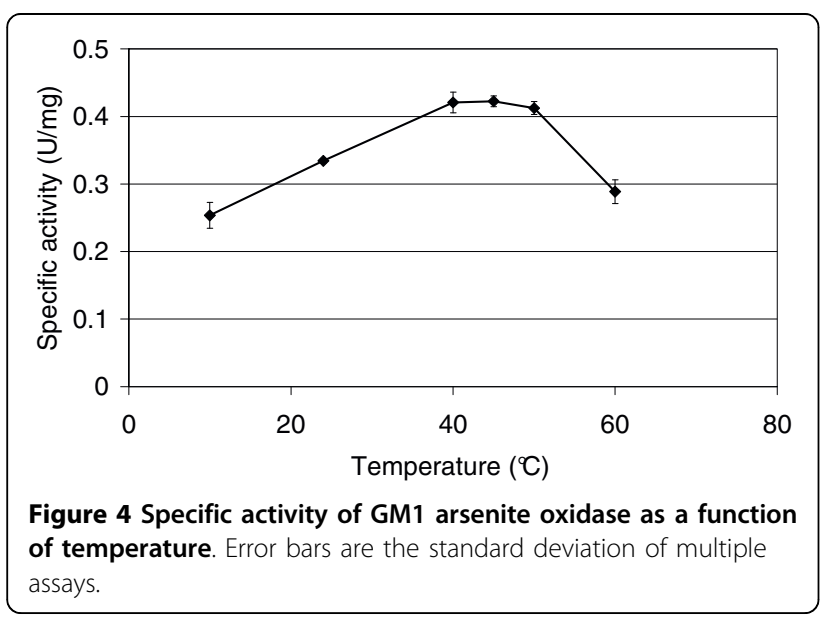

reaching a maximum at temperatures well above the optimum for growth (i.e. between $40-50^{\circ} \mathrm{C}$ ).

The partial aro $A$ gene sequence of GM1 was found to be identical to that of the partial aro $A$ of the putative arsenite oxidiser Limnobacter sp. 83, another member of the Betaproteobacteria [8] but in a different family. No homologues of aroA were found in the genome sequences of GM1's closest relatives, Polaromonas naphthalenivorans CJ2 and Polaromonas sp. JS666; GM1 is thus clearly distinct from the other Polaromonas spp.

To compare the arsenite oxidisers in the top (9.22 $\mathrm{mM}$ arsenite) and bottom (6.01 $\mathrm{mM}$ arsenite) subsamples from the 2007 biofilm, two aroA gene libraries were constructed using a recently developed method [7]. The use of aroA-specific primers has been shown to be a useful approach for detecting and identifying arsenite oxidisers in environmental samples [7-10,19]. Phylogenetic analysis of 100 AroA-like sequences (Figure 5), from 50 top (designated TOP) and 50 bottom (designated BOT) clones, revealed the diversity of arsenite-oxidising bacteria in the two subsamples. The corresponding protein sequences were compared with known and putative AroA sequences and with the sequence obtained from GM1. Eighteen different AroA-like sequences were obtained from the TOP library and ten from BOT; only four were present in both. All but one of the sequences clustered within the Betaproteobacteria; the exception, BOT10, clustered within the Agrobacterium/Rhizobium branch of the Alphaproteobacteria. The TOP8 sequence is closely related (98.7\% sequence identity) to the AroA homologue in Rhodoferax ferrireducens. Apart from BOT10 the AroA-like sequences clustered into three distinct clades (A, B and C), none of which is close to any AroA sequences from known arsenite oxidisers. The BOT7 sequence (clade $C$ ) was identical to the AroA sequence of GM1, so the other sequences in clade C may also come from Polaromonas species. The affinities of the organisms whose AroA sequences lie in clades $\mathrm{A}$ and $\mathrm{B}$ are not known.

Rarefaction curves (Figure 6) of different DNA sequence profiles suggest that the TOP library has higher sequence richness (i.e. more distinct sequences) than the BOT library. Curve saturation was not observed for either library, suggesting that not all of the aroA-like genes present had been detected. A separate rarefaction analysis was performed on the operational taxonomic units (OTUs), where sequences were clustered with BLASTclust based on a $99 \%$ identity threshold. Both OTU curves come close to saturation, approaching similar richness asymptotes; aroA-like OTU richness is similar in TOP and BOT (BOT appears to be slightly more diverse, but the $95 \%$ confidence intervals showed that there was no significant difference). While 50 


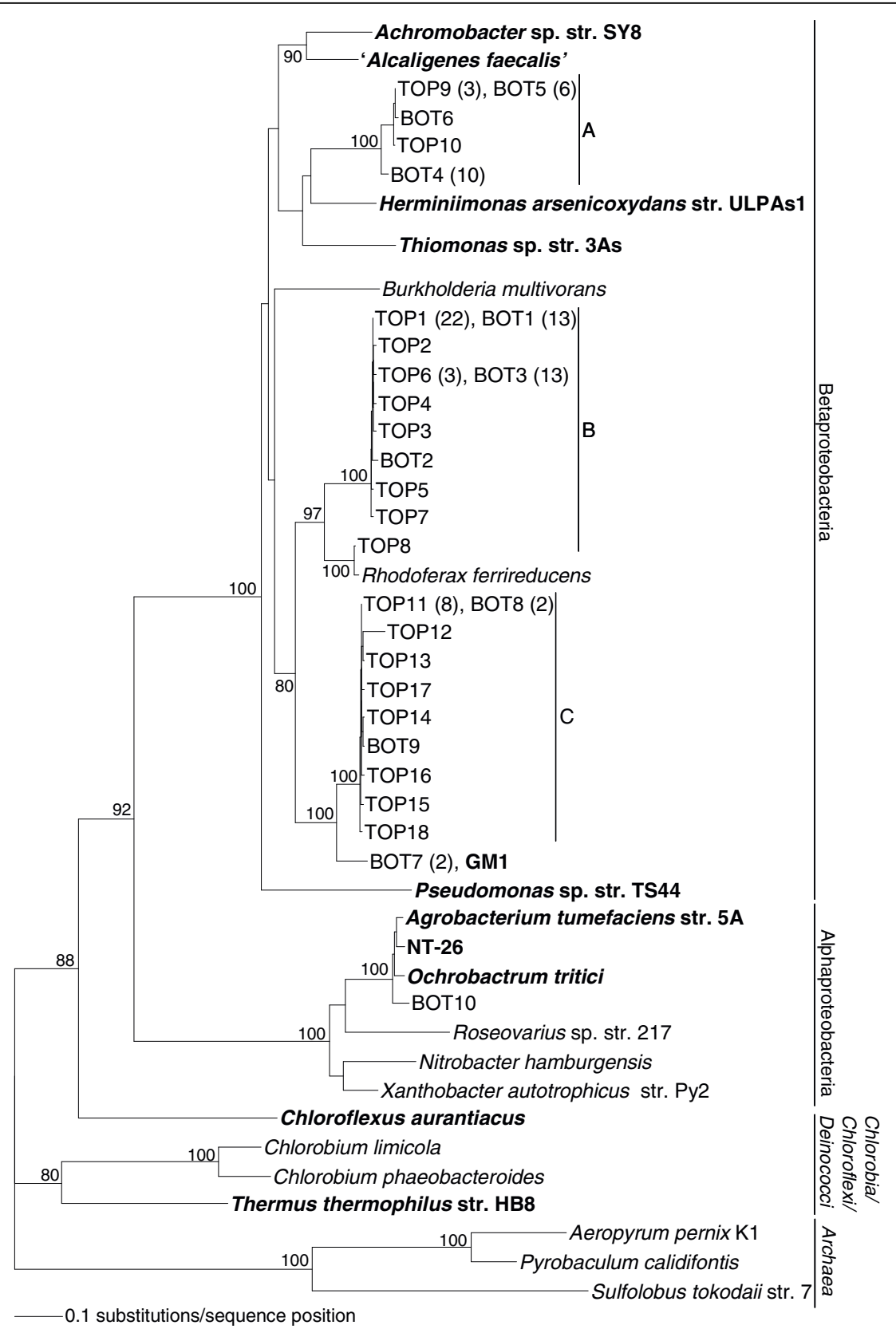

Figure 5 Phylogenetic tree of AroA-like sequences from an arsenic-contaminated biofilm. Phylogenetic analysis of 50 AroA-like sequences from both the top (TOP) and bottom (BOT) of the biofilm. Published AroA sequences are in bold, organisms that contain AroA homologues and the AroA from the arsenite-oxidising bacterium GM1 are also shown. Numbers in parentheses indicate the number of identical sequences represented by each branch. Significant bootstrap values (per 100 trials) of major branch points are shown. Closely related groups of sequences have been designated clades A, B and C. Putative AroA sequences from the Archaea were used to root the tree.

clones may not have yielded the full sequence richness of either library, continued sampling would have been unlikely to reveal significant numbers of additional OTUs.

With almost all sequences represented by only a single clone (Figure 5) sequence diversity (evenness) is inevitably high in both subsamples. Simpson's index [20] does not differ between them (TOP: $\mathrm{D}=0.78$; BOT: $\mathrm{D}=$ 0.82 ). The two subsamples do, however, differ in composition. They are dominated by clones from different clades: TOP by clades B and C; BOT by A and B (Table 1: $\chi^{2}=16.17,2$ d.f. $\left.P<.001\right)$. The difference reflects the numbers of clones from the three clades, rather than the distribution of the sequences. 


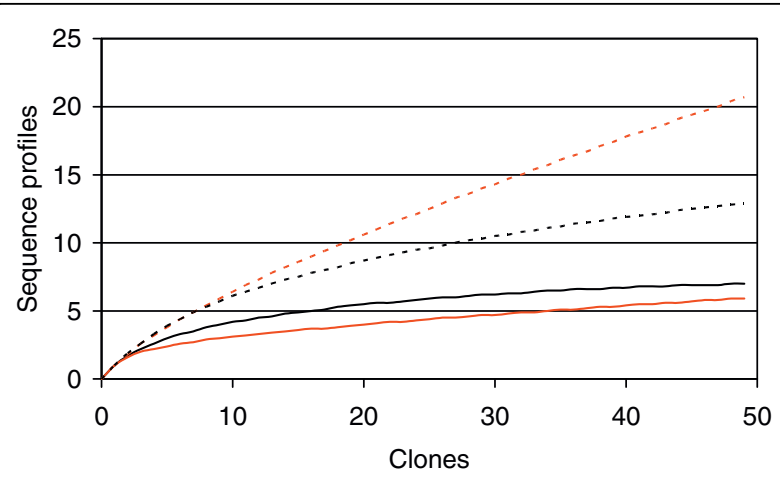

Figure 6 Rarerefaction curves for DNA sequences from aroAlike gene libraries TOP (red) and BOT (black). Dashed lines are for different sequence profiles. Solid lines are for OTUs based on > 99\% sequence identity.

\section{Conclusions}

In this report we provide the first evidence for bacterial arsenite oxidation below $10^{\circ} \mathrm{C}$. The sample site, the Giant Mine, is an extreme environment with arsenic concentrations in excess of $50 \mathrm{mM}$ in the underground waters [21]. In this study we have compared the diversity of arsenite oxidisers in two different subsamples and found that although the composition of arsenite-oxidising communities differs, the diversity does not. The isolated arsenite-oxidising bacterium GM1 was able to grow at low temperatures $\left(<10^{\circ} \mathrm{C}\right)$; its arsenite oxidase was constitutively expressed and displayed broad thermolability.

\section{Methods}

\section{Sample collection and analyses}

Samples were collected from Giant Mine, north of Yellowknife, Northwest Territories, Canada. The microbial biofilm was located growing on a wall in an abandoned stope below the arsenic trioxide storage chambers where liquid was seeping from a diamond drill hole. The first sampling of the biofilm was done in July 2006 and involved collecting some of the biofilm itself, coexisting seepage water, and mineral precipitates from near the top of the biofilm. The biofilm was re-sampled in May 2007 using the same sampling method as in 2006 but this time two samples were collected: one at the top near the seepage point and another near the bottom. All samples were kept at $4^{\circ} \mathrm{C}$ at all times until microbial or chemical analyses could be performed.

Table 1 The number of clones from TOP and BOT that clustered within clades $A, B$ and $C$

\begin{tabular}{llll}
\hline Clade & TOP & BOT & Total \\
\hline A (\%) & $4(19 \%)$ & $17(81 \%)$ & $\mathbf{2 1}$ \\
B (\%) & $30(53 \%)$ & $27(47 \%)$ & $\mathbf{5 7}$ \\
C (\%) & $15(83 \%)$ & $3(17 \%)$ & $\mathbf{1 8}$ \\
\hline
\end{tabular}

The 2006 biofilm sample was used for mineral characterisation. Mineral precipitates were characterised using beamline X26A at the National Synchrotron Light Source. MicroXANES (at the arsenic K edge) and microXRD followed methods similar to those described previously [22]. The XANES spectra collected on thin layers on sample powder provided clear indication of the presence of both arsenite and arsenate, and a linear combination fit, using scorodite $\left(\mathrm{As}^{\mathrm{V}}\right)$ and schneiderhohnite $\left(\mathrm{As}^{\mathrm{III}}\right)$ as model compounds, estimated the relative proportions at $57 \%$ arsenate and $43 \%$ arsenite. Synchotron-based microXRD of the biofilm showed clear evidence of microcrystalline yukonite, a $\mathrm{Ca}-\mathrm{Fe}$ arsenate $\left[\mathrm{Ca}_{7} \mathrm{Fe}\left(\mathrm{AsO}_{4}\right)_{9} \mathrm{O}_{10} \cdot 24.3 \mathrm{H}_{2} \mathrm{O}\right]$ [22] (see reddishbrown colouration in Figure 1a), gypsum and an arsenite mineral [either claudetite $\left(\mathrm{As}_{2} \mathrm{O}_{3}\right)$ or manganarsite $\left.\left(\mathrm{Mn}_{3} \mathrm{As}_{2} \mathrm{O}_{4}(\mathrm{OH})_{4}\right)\right]$.

\section{Arsenic analyses}

In 2006 the liquid from the biofilm was extracted 18 days after collection whereas in 2007 the liquid was extracted immediately after collection. The liquid was extracted using a syringe with a $0.22-\mu \mathrm{m}$ filter. Concentrations of total arsenic and arsenite were determined by hydride generation atomic-absorption spectrometry (HG-AAS) using a Perkin Elmer - Analyst 300.

Cultures were analysed for total arsenic and arsenite using a JY Ultima 2C ICP-OES using the methods described previously [23-25].

\section{Scanning electron microscopy}

Samples from the top and bottom of the 2007 microbial biofilm were examined using a Jeol JSM-6480LV high-performance, variable pressure analytical scanning electron microscope (SEM) operating in low-vacuum mode using 7-11 kV accelerating voltage and a spot size of $29 \mathrm{~nm}$. Prior to examination, samples were mounted on $12.5-\mathrm{mm}$ pin stubs with sticky carbon discs, freeze-dried in liquid nitrogen using a MODULO $4 \mathrm{k}$ instrument for $30 \mathrm{~min}$ utes, and gold coated using a Polaron E5000 instrument.

\section{Enrichment and isolation}

In 2006 samples of the microbial biofilm $(0.5 \mathrm{~g})$ were inoculated into the MSM [15] containing $4 \mathrm{mM}$ arsenite and incubated at $4{ }^{\circ} \mathrm{C}, 10^{\circ} \mathrm{C}$ and $20^{\circ} \mathrm{C}$. The enrichments were incubated until all the arsenite was oxidised. The biofilm enrichments took two days to oxidise the $4 \mathrm{mM}$ arsenite irrespective of temperature (data not shown). The enrichments were subcultured three times in the MSM containing $4 \mathrm{mM}$ arsenite before they were serially diluted and plated onto MSM containing $4 \mathrm{mM}$ arsenite and 1.5\% (w/v) purified agar (Oxoid). Individual colonies were purified and tested for both chemolithoautotrophic [containing $0.05 \%(\mathrm{w} / \mathrm{v}) \mathrm{NaHCO}_{3}$ as 
carbon source] and heterotrophic (containing 0.04\% $(w / v)$ yeast extract) growth with arsenite [15].

\section{Growth of GM1}

Growth experiments of GM1 were conducted in MSM containing $0.04 \%(\mathrm{w} / \mathrm{v})$ yeast extract in the presence and absence of $4 \mathrm{mM}$ arsenite at $4^{\circ} \mathrm{C}, 10^{\circ} \mathrm{C}$ and $20^{\circ} \mathrm{C}$ with shaking at $130 \mathrm{rpm}$ in batch cultures. Experiments were commenced with a $5 \%(\mathrm{v} / \mathrm{v})$ inoculum of late exponential phase cells grown in the same medium at the same temperature. At regular time intervals samples were taken to measure optical density and $\mathrm{pH}$, and for arsenic analyses. Samples for arsenic analyses were centrifuged in a benchtop centrifuge and the supernatant stored at $-20^{\circ} \mathrm{C}$ until required. All growth experiments were performed on at least two separate occasions with two to three replicates.

\section{Arsenite oxidase assays}

GM1 cultures were harvested and crude cell extracts produced by passing them through a French pressure cell at $14 \mathrm{kPSI}$ and arsenite oxidase activity determined by measuring the reduction of the artificial electron acceptor 2,6-dichlorophenolindophenol [15]. All assays were performed in the optimum buffer for the enzyme, $50 \mathrm{mM}$ MES buffer (pH 5.5). Reactions were incubated at the specific temperature with a Cary Dual Cell Peltier for 5 mins prior to the addition of arsenite.

16S rRNA gene sequence determination and phylogenetic analyses

Genomic DNA was extracted using the Wizard ${ }^{\oplus}$ Genomic DNA purification kit (Promega). 16S rDNA was amplified by PCR using the $27 \mathrm{f}$ and $1525 \mathrm{r}$ primers described previously [26], with Phusion high fidelity DNA polymerase (New England Biolabs) under the following conditions: $98^{\circ} \mathrm{C}$ for $30 \mathrm{~s}$, followed by 40 cycles of $98^{\circ} \mathrm{C}$ for $30 \mathrm{~s}, 55^{\circ} \mathrm{C}$ for $30 \mathrm{~s}$ and $72^{\circ} \mathrm{C}$ for $90 \mathrm{~s}$ with a final extension at $72^{\circ} \mathrm{C}$ for $10 \mathrm{~min}$. Both strands of the PCR product were sequenced at the Wolfson Institute for Biomedical Research (WIBR) (UCL) using the primers 27f, 342r, 357f, 518r, 530f, 1100r, 1114f, 1392r, 1406f, 1492r and 1525r [26]. [GM1 16S rRNA gene sequence GenBank accession number: EU106605].

\section{Amplification of aroA, library construction and sequencing}

Genomic DNA was extracted from GM1 using the Wizard $^{\oplus}$ Genomic DNA purification kit (Promega) and from the top and bottom biofilm samples using the PowerSoil DNA isolation kit (MoBio Laboratories). The degenerate oligonucleotides used to amplify a portion of the $\operatorname{aro} A$ gene were primer set \#2 as described previously [7] using Phusion high fidelity DNA polymerase (New England Biolabs). The aroA PCR products from
GM1 and the two biofilm samples were cloned into pBluescript II KS+ (Stratagene). Both strands of the cloned GM1 aro $A$ gene and 50 individual aro $A$ clones from each library were sequenced using the T7 and T3 promoter primers at the WIBR (UCL). Database searches were performed using BLASTP [27]. [GM1 partial aro $A$ sequence GenBank accession number: EU106602. The TOP and BOT aro $A$ library sequences GenBank accession numbers: FJ151018-FJ151051].

\section{Phylogenetic analysis}

Sequences were aligned with CLUSTALX 2.0 [28] using default settings and were manually edited. Phylogenetic analyses were performed with PHYLIP 3.67 [29] and trees constructed and edited with TREEVIEW [30]. Nucleotide and protein distance analyses were performed with the F84 and Jones-Taylor-Thornton computations, respectively and the trees constructed using the neighbour-joining method using a boostrap value of 100 .

Accession numbers of reference sequences used in AroA phylogenetic analysis are given in parentheses following the organism name: Achromobacter sp. str. SY8 (ABP63660), Aeropynum pernix (NP_148692), Agrobacterium tumefaciens str. 5A (ABB51928), 'Alcaligenes faecalis' (AAQ19838), Burkholderia multivorans (YP_001585661), Chlorobium limicola (ZP_00512468), Chlorobium phaeobacteroides (ZP_00530522), Chloroflexus aurantiacus (YP_001634827), Herminiimonas arsenicoxydans (YP_001098817), Nitrobacter hamburgensis (YP_571843), NT-26 (AAR05656), Ochrobacterum tritici (ACK38267), Pseudomonas sp. str. TS44. (ACB05943), Pyrobaculum calidifontis (YP_001056256), Rhodoferax ferrireducens (YP_524325), Roseovarius sp. 217 (ZP_01034989), Thermus thermophilus str. HB8 (YP_145366), Thiomonas sp. 3As (CAM58792), Sulfolobus tokodaii str. 7 (NP_378391) and Xanthobacter autotrophicus Py2 (YP_001418831).

\section{Rarefaction curves and Chi-squared}

Rarefaction calculations were performed to compare the DNA sequence diversity of the TOP and BOT libraries, and to assess whether full coverage of sequence diversity was obtained. This was performed with the program ANALYTICAL RAREFACTION 1.3 http://www.uga. $\mathrm{edu} / \sim$ strata/software/index.html which uses the rarefaction calculations given by Hulbert [31] and Tipper [32]. Sequences were clustered with BLASTclust http:// toolkit.tuebingen.mpg.de/blastclust\# based on a $99 \%$ identity threshold over $100 \%$ of the sequence length to create operating taxonomic units.

\section{Acknowledgements}

JMS would like to acknowledge support from the University of London Central Research fund (Grant AR/CRF/B). THO is supported by a Natural 
Environment Research Council studentship (14404A). HEJ and SRW acknowledge support from Natural Sciences and Engineering Research Council and Indian and Northern Affairs Canada, and from A. Lanzirotti at the National Synchrotron Light Source. DKN acknowledges support from the National Research Program of the US Geological Survey. We would like to thank R. Blaine McCleskey with technical help for biofilm arsenic analyses, James Davy for technical help with the SEM, Anthony Osborn for ICP-OES analysis of culture solutions, and S. Simpson for the underground photograph of the biofilm. Any use of trade, product, or firm names is for descriptive purposes only and does not imply endorsement by the USGS.

\section{Author details}

'Institute of Structural and Molecular Biology, UCL, Darwin Building, Gower Street, London WC1E 6BT, UK. ${ }^{2}$ Department of Geological Sciences and Geological Engineering, Queen's University, Kingston, Ontario K7L 3N6, Canada. ${ }^{3}$ Department of Earth and Planetary Sciences, Birkbeck, University of London, Malet Street, London WC1E 7HX, UK. ${ }^{4}$ US Geological Survey Boulder, Colorado 80303, USA. ${ }^{5}$ Research Department of Genetics, Evolution and Environment, UCL, Darwin Building, Gower Street, London WC1E 6BT, UK.

\section{Authors' contributions}

THO performed the majority of the experiments (clone libraries, $16 \mathrm{~S}$ rRNA gene sequencing, phylogenetic analyses, GM1 growth experiments and enzyme assays). HEJ collected the samples from Giant Mine and oversaw the mineral characterisation. $\mathrm{KAH}-\mathrm{E}$ did the arsenic analyses for the growth experiments. SRW performed the mineral characterisation of the biofilm. DKN oversaw the chemical analyses of the biofilm samples. SAW advised on the statistical analyses and edited the manuscript. JMS isolated GM1 and the DNA from the biofilm, conceived and coordinated the study. All authors read and approved the final version of the manuscript.

\section{Received: 17 May 2010 Accepted: 30 July 2010 Published: 30 July 2010}

\section{References}

1. Cullen WR: Is Arsenic an Aphrodisiac? The Sociochemistry of an Element. UK: Royal Society of Chemistry Publishing 2008.

2. Nordstrom DK: Worldwide occurrences of arsenic in ground water. Science 2002, 296:2143-2145.

3. Ravenscroft P, Brammer H, Richards K: Arsenic Pollution: a Global Synthesis. UK: Wiley-Blackwell 2009

4. Smedley PL, Kinniburgh DG: A review of the source, behaviour and distribution of arsenic in natural waters. Appl Geochem 2002, 17:517-568.

5. Oremland RS, Stolz JF: The ecology of arsenic. Science 2003, 300:939-944.

6. Stolz JF, Basu P, Santini JM, Oremland RS: Arsenic and selenium in microbial metabolism. Annu Rev Microbiol 2006, 60:107-130.

7. Inskeep WP, Macur RE, Hamamura N, Warelow TP, Ward SA, Santini JM: Detection, diversity and expression of aerobic bacterial arsenite oxidase genes. Environ Microbiol 2007, 9:934-943.

8. Quéméneur $M$, Heinrich-Salmeron $A$, Muller $D$, Lièvremont $D$, Jauzein $M$, Bertin PN, Garrido F, Joulian C: Diversity surveys and evolutionary relationships of $a$ oxB genes in aerobic arsenite-oxidising bacteria. Appl Environ Microbiol 2008, 74:4567-4573.

9. Quéméneur M, Cébron A, Billard P, Battaglia-Brunet F, Garrido F, Leyval C, Joulian C: Population structure and abundance of arsenite-oxidising bacteria along an arsenic pollution gradient in waters of the Upper Isle River Basin, France. Appl Environ Microbiol 2010, 76:4566-4570.

10. Rhine ED, Garcia-Dominguez E, Phelps CD, Young LY: Environmental microbes can speciate and cycle arsenic. Environ Sci Technol 2005, 39:9569-9573.

11. Clark ID, Raven KG: Sources and circulation of water and arsenic in the Giant Mine, Yellowknife, NWT, Canada. Isotopes Environ Health Stud 2004 40:1-14

12. Coleman NV, Mattes TE, Gossett JM, Spain JC: Biodegradation of cisdichloroethene as the sole carbon source by a $\beta$-Proteobacterium. Appl Environ Microbiol 2002, 68:2726-2730.

13. Jeon CO, Park W, Padmanabhan, DeRito C, Snape JR, Madsen EL: Discovery of a bacterium, with distinctive dioxygenase, that is responsible for in situ biodegradation in contaminated sediment. Proc Natl Acad Sci USA 2003, 100:13591-13596.
14. Wang Q, Garrity GM, Tiedje JM, Cole JR: Naïve Bayesian classifier for rapid assignment of rRNA sequences into the new bacterial taxonomy. Appl Environ Microbiol 2007, 73:5261-5267.

15. Santini JM, Sly LI, Schnagl RD, Macy JM: A new chemolithoautotrophic arsenite-oxidising bacterium isolated from a gold mine: phylogenetic, physiological, and preliminary biochemical studies. Appl Environ Microbiol 2000, 66:92-97.

16. Drewniak L, Matlakowska R, Sklodowska A: Arsenite and arsenate metabolism of Sinorhizobium sp. M14 living in the extreme environment of Zloty Stok gold mine. Geomicrobiol J 2008, 22:363-370.

17. Duquense K, Lieutaud A, Ratouchniak J, Muller D, Lett M, Bonnefoy V: Arsenite oxidation by a chemoautotrophic moderately acidophilic Thiomonas sp.: from the strain to gene study. Environ Microbiol 2008, 10:228-237.

18. Kashyap DR, Botero LM, Franck WL, Hassett DJ, McDermott TR: Complex regulation of arsenite oxidation by Agrobacterium tumefaciens. J Bacteriol 2006, 188:1081-1088.

19. Hamamura N, Macur RE, Korf S, Ackerman G, Taylor WP, Kozubal M, Reysenbach A-L, Inskeep WP: Linking microbial oxidation of arsenic with detection and phylogenetic analysis of arsenite oxidase genes in diverse geothermal environments. Environ Microbiol 2009, 11:421-431.

20. Magurran AE: Ecological diversity and its measurement. London: Chapman 1996.

21. Cullen WR, Polishchuk E, Reimer KJ, Sun YM, Wang L, Lai WWM: Arsenic in Yellowknife, North West Territories, Canada. Arsenic exposure and health effects V USA: ElsevierChappell WR, Abernathy CO, Calderson RL, Thomas DJ 2003, 79-88.

22. Walker SW, Jamieson HE, Lanzirotti A, Andrade CF: Determining arsenic speciation in iron oxides derived from a gold-roasting operation: application of synchrotron micro-XRD and micro-XANES at the grain scale. Can Mineral 2005, 43:1205-1224.

23. Meng SG, Bang SB, Korfiatis GP: Effects of silicate, sulphate, and carbonate on arsenic removal by ferric chloride. Water Res 2000, 34:1255-1261.

24. Meng XG, Korfiatis GP, Jing CY, Christodoulatos C: Redox transformations of arsenic in water treatment sludge during aging and TCLP extraction. Environ Sci Technol 2001, 35:3476-3481.

25. Tu S, Ma LQ, MacDonald GE, Bondada B: Effects of arsenic species and phosphorus on arsenic absorption, arsenate reduction and thiol formation in excised parts of Pteris vittata L. Environ Exp Bot 2004 51:121-131.

26. Lane DJ: $16 \mathrm{~S} / 23 \mathrm{~S}$ rRNA sequencing. Nucleic Acid Techniques in Bacterial Systematics UK: John Wiley \& SonsStackebrandt E, Goodfellow M 1991, 115-163.

27. Alschul SF, Gish W, Miller W, Myers EW, Lipman DJ: Basic local alignment search tool. J Mol Biol 1990, 215:403-10.

28. Thompson JD, Gibson TJ, Plewniak F, Jeanmougin F, Higgins DG: The ClustalX windows interface: flexible strategies for multiple sequence alignment aided by quality analysis tools. Nucl Acids Res 1997 , 25:4876-4882.

29. Felsenstein J: PHYLIP - Phylogeny Inference Package (Version 3.2). Cladistics 1989, 5:164-166.

30. Page RDM: TREEVIEW: An application to display phylogenetic trees on personal computers. Comput Appl Biosci 1996, 12:357-358.

31. Hurlbert SH: The nonconcept of species diversity: a critique and alternative parameters. Ecology 1971, 52:577-586.

32. Tipper JC: Rarefaction and rarefiction - the use and abuse of a method in paleontology. Paleobiol 1979, 5:423-434.

\section{doi:10.1186/1471-2180-10-205}

Cite this article as: Osborne et al: Microbial oxidation of arsenite in a subarctic environment: diversity of arsenite oxidase genes and identification of a psychrotolerant arsenite oxidiser. BMC Microbiology 2010 10:205 